\title{
Feature Extraction using Local Binary Pattern: An Application for Illumination Invariant Facial Expression Recognition
}

\author{
Zankhana H. Shah \\ Department of Information Technology, \\ Birla Vishvakarma Mahavidyalaya, Anand, Gujarat, India \\ Dr. Vikram Kaushik \\ Manish Institute of Computer Studies \\ Visnagar, Gujarat, India
}

\begin{abstract}
Facial expressions play an important role in the area of human computer interaction. They are most commonly used for interpretation of human emotions. Three are 6 emotions which are universally accepted. They are happy, sad, angry, disgust, fear, and surprise. In this paper, application of local binary pattern (LBP) for facial expression recognition in different illumination conditions has shown. The proposed method consists of mainly three sub tasks: Pre-processing, Facial feature extraction and Facial expression classification. LBP is used for feature extraction. The extracted features are used as an input to the classifier for expression classification. For experimental purpose, the JAFFE (Japanese Female Facial Expression) database and self created database containing images with variation in illumination are used.
\end{abstract}

Keywords-Feature Extraction, Local Binary Pattern, Illumination Variation, Expression Classification.

\section{INTRODUCTION}

Facial expressions are most powerful means for humans to express their emotions and intensions. A study by Mehrabian [1] says that $7 \%$ of message is expressed by words, $38 \%$ by voice pitch while $55 \%$ of message is conveyed by facial expressions. Facial expressions play an important role in human communications. Humans are capable of producing hundreds of facial actions during communication that carries different meaning. According to Ekman's theory [2], excluding neutral, there are six expressions that are universal for people of different nations and cultures. Those basic expressions are happy, sad, angry, disgust, fear, and surprise.

Numerous applications of automated facial expression recognition system include automated tools for behavioral research, psychological studies, face animation, speech synthesis, lip reading, video conferencing, robotics and many more [3].

Facial expression recognition task is considered to be very challenging task due to many reasons. Expressions vary from persons to persons. Also, the expressions do change at time and also depend on human mood. The most challenging problems in the task of facial expression recognition include variation in lighting condition, also known as illumination, non-frontal face images, that is pose variance and the occlusions, that is the presence of hair, various accessories like glasses etc.

Variation in lighting conditions affects the feature extraction process. The changes in illumination may make some of the features invisible or lightly visible, which finally may affect on the classification. Similarly, occlusion like presence of hair or spectacles may obscure some part of the face. Occlusions can introduce errors into the predicted expression or result in an incorrect expression due to the loss of few of the important features. Also, non-frontal faces need to be taken care differently. Here too, some part of the face will be invisible which will make feature extraction process more complex.

Plenty of work has been done on facial expression recognition [16-21]. An automatic classification of facial expressions consists of two stages: feature extraction and feature classification. The feature extraction is extremely important to the whole classification process. If insufficient features are used, even the best classifier could fail to achieve accurate recognition. In most cases of facial expression classification, feature extraction process produces sufficiently large number of features and consequently a smaller sub-set of features needs to be selected according to some optimality criteria.

This paper addresses the issue of change in illumination for facial expression recognition where Local Binary Pattern is used for feature extraction. The work presented here is experimented on two databases. JAFFE [15] (Japanese Female Facial Expressions) database contains images of different expressions of 10 subjects with different lighting conditions. Another database used for the experiments is self created. It also contains images of different expressions of 10 subjects, 08 female and 02 male, with different lighting conditions. Preprocessing 
operations have been performed to normalize the image. Local binary pattern method is used for extracting features of the expressions. Finally, classification is done with the help of neural network.

The rest of the paper is organized as follows. Section 2 describes the facial expression recognition methodology with necessary steps to be followed. In section 3, LBP method, used for the feature extraction purpose, is described. Section 4 gives analysis of results. Section 5 summarizes the overall work.

\section{FACIAL EXPRESSION RECOGNITION METHODOLOGY}

As shown in figure 1, facial expression recognition is a process which consists of following three steps [IEEE paper].

- Pre-processing the image

- Extracting facial expression features from normalized image. This can be done by analyzing the change in the appearance of facial features or change in the location of facial features.

- Classification of expressions into six universal categories such as angry, happy, disgust, fear, sad and surprise with the help of extracted features.

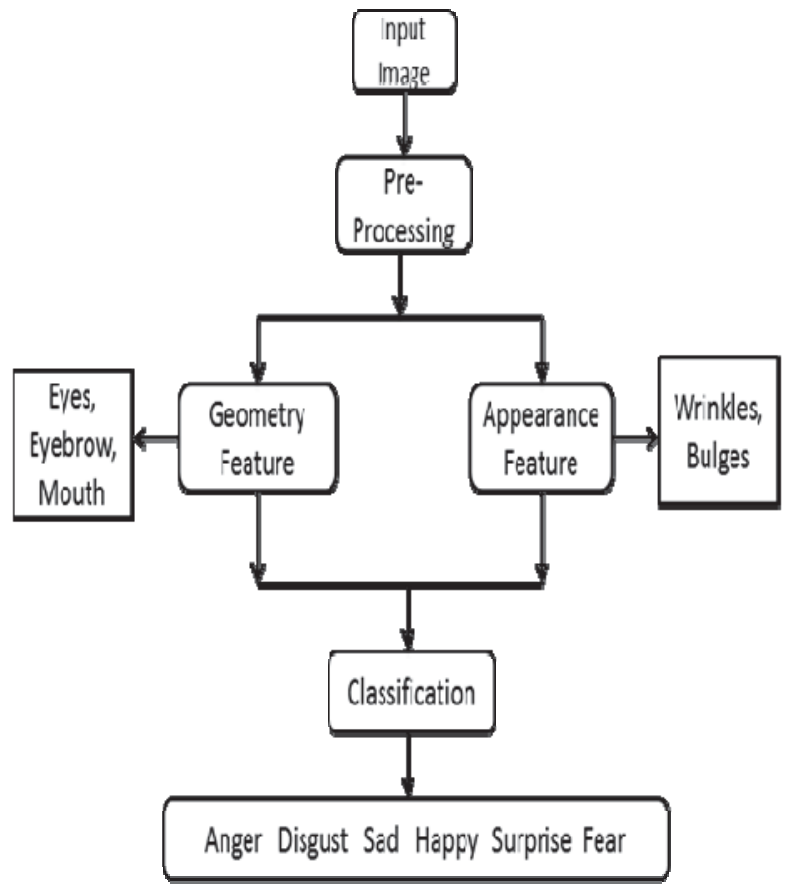

Figure1. FER Methodology

\section{A. Pre-processing:}

Recently, more researchers focus on robust facial expression recognition such as expression recognition systems invariant to pose and illumination variations. Illumination variation is still a challenging problem in face recognition research area, especially for appearance-based approaches. The same person can appear greatly different under varying lighting conditions. The human visual system usually cares about the main features of a face, such as the shapes and relative positions of the main facial features.

There are two approaches to deal with this issue. One approach is to apply image pre-processing techniques which normalize the images to appear stable under different lighting conditions. This approach removes illumination variations while keeping the main facial features unimpaired. Histogram equalization (HE), Gamma correction, logarithm transform, DCT normalization etc. are widely used for illumination normalization [4], [5], [6].

Second approach attempts to extract facial features which are invariant to illumination variations. Edge maps, derivatives of the gray-level, Gabor-like filters and Local binary pattern are few of the methods used for the stated purpose [7] [8].

\section{B. Feature Extraction:}

Feature extraction is the most important part of expression recognition process. Features are the characteristics of the face which carries significant amount of information about expressions. The recognition rate of the system highly depends upon how accurate the extracted features are. 
For an expression recognition process, features that are generated by contractions of facial muscles are considered. It includes deformation of facial features such as eye lids, eye brows, nose, lips, mouth etc. Based upon the type of features, the feature extraction approaches are divided into two categories [9]:

- Focusing on facial features or areas that are prone to change with facial expressions.

- Focusing on those features which would be generated due to facial expressions.

C. Classification:

After the face and its appearance have been perceived, the next step of an automated expression analyzer is to identify the facial expression conveyed by the face. A fundamental issue about the facial expression classification is to define a set of categories we want to deal with. Facial expressions can be classified in various categories such as Anger, Disgust, Sad, Happy, Surprise and Fear [9] [10], as shown in figure 2 .

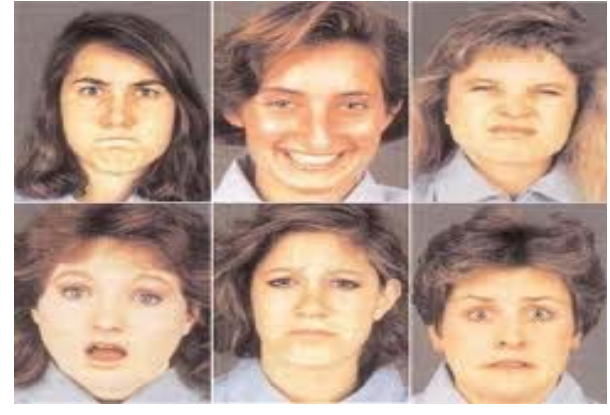

Figure2. Universal Facial Expressions

The most popular classification methods include nearest neighbour, K-means classifier, neural network, and SVM.

The LBP operator was originally designed for texture description. The operator assigns a label to every pixel of an image by thresholding the 33-neighborhood of each pixel with the center pixel value and considering the result as a binary number. Then, the histogram of the labels can be used as a texture descriptor.

\section{FEATURE EXTRACTION USING LOCAL BINARY PATTERN}

LBP features were proposed originally for texture analysis [11] and recently have been introduced to represent faces in facial image analysis [12-14]. The most important properties of LBP features are their tolerance against illumination changes as well as their computational simplicity.

The LBP operator labels the pixel of an image by thresholding a $3 * 3$ neighborhood of each pixel with the centered value and considering the result as a binary number (as shown in Figure 3) and 256-bin histogram of the LBP labels computed over region is used as a texture descriptor. The derived binary numbers (called LBP features or LBP codes) represents texture features including different types of curved edges, spots, flat areas, etc (as shown in Figure 4).

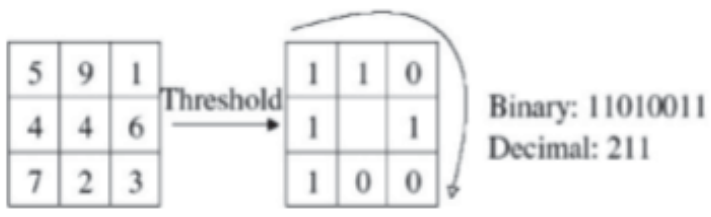

Figure3: The Basic LBP Operator

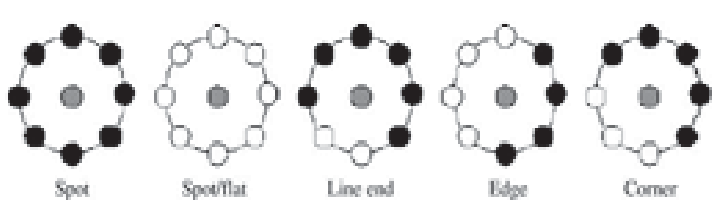

Figure4: Texture primitives which can be detected by LBP

After labeling an image with LBP operator, histogram of the labeled image F1(x, y) can be defined as

$H E=\sum_{n y} I(F 1(x, y)=0, f=0,1 \ldots n-1$ 
Where $\mathrm{n}$ is number of different labels produced by the LBP operator and

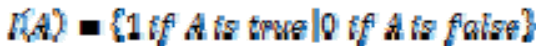

This LBP histogram contains information about the distribution of the local micro patterns; such as edges, spot and flat areas over the whole image, so it can be used to statically describe image characteristics.

\section{IMPLEMENTATION}

The work in this paper presents an efficient illumination invariant facial expression recognition system using Local Binary Pattern. JAFFE (Japanese Female Facial Expression) database is used which contains 177 images of 6 facial expressions posed by 10 Japanese female models. IFE (Indian Facial Expression) database is used which also contain 177 images of 6 facial expressions posed by 10 Indian people including 2 males and 8 females. The IFE database is self created database. The expressions in this database are posed by Indian people.

Classification of expressions into six universal categories, [9][10] such as smile, happy, anger, disgust, sad and fear have been done with two approaches: Euclidian distance and Neural Network.

Euclidian distance is the measure between the features of input image and database images. The feature vector obtained from LBP histogram of the input image is compared with database images with the help of Euclidian distance. The one which is having minimum Euclidian distance is considered as best match.

In the case of classification using Neural Network approach, a feed forward neural network is used.

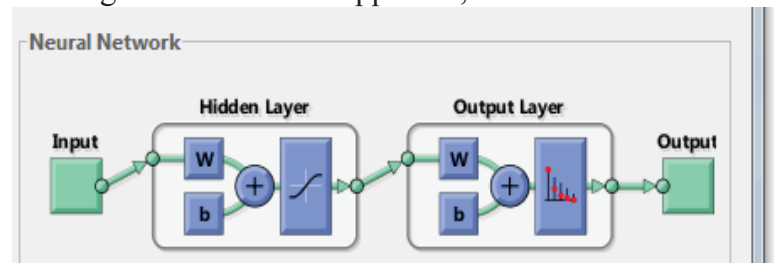

Figure5: Neural Network Architecture

In this network, input layer contains 256 neurons as LBP histogram with 256 bins is extracted from each input image and to be given as an input. The number of neurons in hidden layers is taken as 35 and output layer contains 6 neurons as there are 6 expressions to be classified.

\section{EXPERIMENTAL RESULTS}

The results for each stage mentioned above are collected separately. The results are collected and analyzed for two databases viz. JAFFE and IFE. Also, the analysis has been shown between the results of two classifiers for both databases mentioned above.

\section{A. Result of LBP feature:}
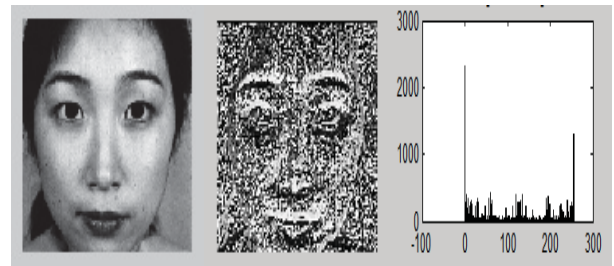

(a)

(b)

(c)

Figure6. (a) Input Image (b) LBP features (c) histogram of LBP features

\section{B. Result of classification using Euclidian Distance:}




\begin{tabular}{|c|c|c|c|c|c|c|c|}
\hline & \multicolumn{7}{|c|}{ Confusion Matrix } \\
\hline 1 & $\begin{array}{c}\mathbf{0} \\
0.0 \%\end{array}$ & $\begin{array}{c}1 \\
6.7 \%\end{array}$ & $\begin{array}{c}\mathbf{0} \\
0.0 \%\end{array}$ & $\begin{array}{c}\mathbf{0} \\
0.0 \%\end{array}$ & $\begin{array}{c}\mathbf{0} \\
0.0 \%\end{array}$ & $\begin{array}{c}\mathbf{0} \\
0.0 \%\end{array}$ & $\begin{array}{l}0.0 \% \\
100 \%\end{array}$ \\
\hline 2 & $\begin{array}{c}2 \\
13.3 \%\end{array}$ & $\begin{array}{c}1 \\
6.7 \%\end{array}$ & $\begin{array}{c}\mathbf{0} \\
0.0 \%\end{array}$ & $\begin{array}{c}\mathbf{0} \\
0.0 \%\end{array}$ & $\begin{array}{c}\mathbf{0} \\
0.0 \%\end{array}$ & $\begin{array}{c}\mathbf{0} \\
0.0 \%\end{array}$ & $\begin{array}{l}33.3 \% \\
66.7 \%\end{array}$ \\
\hline & $\begin{array}{c}\mathbf{0} \\
0.0 \%\end{array}$ & $\begin{array}{c}\mathbf{0} \\
0.0 \%\end{array}$ & $\begin{array}{c}3 \\
20.0 \%\end{array}$ & $\begin{array}{c}\mathbf{0} \\
0.0 \%\end{array}$ & $\begin{array}{c}\mathbf{0} \\
0.0 \%\end{array}$ & $\begin{array}{c}\mathbf{0} \\
0.0 \%\end{array}$ & $\begin{array}{l}100 \% \\
0.0 \%\end{array}$ \\
\hline & $\begin{array}{c}\mathbf{0} \\
0.0 \%\end{array}$ & $\begin{array}{c}\mathbf{0} \\
0.0 \%\end{array}$ & $\begin{array}{c}\mathbf{0} \\
0.0 \%\end{array}$ & $\begin{array}{c}1 \\
6.7 \%\end{array}$ & $\begin{array}{c}\mathbf{0} \\
0.0 \%\end{array}$ & $\begin{array}{c}\mathbf{0} \\
0.0 \%\end{array}$ & $\begin{array}{l}100 \% \\
0.0 \%\end{array}$ \\
\hline & $\begin{array}{c}\mathbf{0} \\
0.0 \%\end{array}$ & $\begin{array}{c}\mathbf{0} \\
0.0 \%\end{array}$ & $\begin{array}{c}1 \\
6.7 \%\end{array}$ & $\begin{array}{c}\mathbf{0} \\
0.0 \%\end{array}$ & $\begin{array}{c}3 \\
20.0 \%\end{array}$ & $\begin{array}{c}\mathbf{0} \\
0.0 \%\end{array}$ & $\begin{array}{l}75.0 \% \\
25.0 \%\end{array}$ \\
\hline 6 & $\begin{array}{c}\mathbf{0} \\
0.0 \%\end{array}$ & $\begin{array}{c}\mathbf{0} \\
0.0 \%\end{array}$ & $\begin{array}{c}\mathbf{0} \\
0.0 \%\end{array}$ & $\begin{array}{c}\mathbf{0} \\
0.0 \%\end{array}$ & $\begin{array}{c}\mathbf{0} \\
0.0 \%\end{array}$ & $\begin{array}{c}3 \\
20.0 \%\end{array}$ & $\begin{array}{l}100 \% \\
0.0 \%\end{array}$ \\
\hline & $\begin{array}{l}0.0 \% \\
100 \%\end{array}$ & $\begin{array}{l}50.0 \% \\
50.0 \%\end{array}$ & $\begin{array}{l}75.0 \% \\
25.0 \%\end{array}$ & $\begin{array}{l}100 \% \\
0.0 \%\end{array}$ & $\begin{array}{l}100 \% \\
0.0 \%\end{array}$ & $\begin{array}{l}100 \% \\
0.0 \%\end{array}$ & $\begin{array}{l}73.3 \% \\
26.7 \%\end{array}$ \\
\hline & 1 & 2 & & 4 & 5 & 6 & \\
\hline
\end{tabular}

C. Result of classification using Neural Network:

\begin{tabular}{|c|c|c|c|c|c|c|c|}
\hline & \multicolumn{7}{|c|}{ Confusion Matrix } \\
\hline 1 & $\stackrel{1}{16.7 \%}$ & $\begin{array}{c}\mathbf{0} \\
0.0 \%\end{array}$ & $\begin{array}{c}\mathbf{0} \\
0.0 \%\end{array}$ & $\begin{array}{c}\mathbf{0} \\
0.0 \%\end{array}$ & $\begin{array}{c}\mathbf{0} \\
0.0 \%\end{array}$ & $\begin{array}{c}\mathbf{0} \\
0.0 \%\end{array}$ & $\begin{array}{l}100 \% \\
0.0 \%\end{array}$ \\
\hline 2 & $\begin{array}{c}\mathbf{0} \\
0.0 \%\end{array}$ & $\begin{array}{c}\mathbf{0} \\
0.0 \%\end{array}$ & $\begin{array}{c}\mathbf{0} \\
0.0 \%\end{array}$ & $\begin{array}{c}\mathbf{0} \\
0.0 \%\end{array}$ & $\begin{array}{c}\mathbf{0} \\
0.0 \%\end{array}$ & $\begin{array}{c}\mathbf{0} \\
0.0 \%\end{array}$ & $\begin{array}{l}\text { NaN\% } \\
\text { NaN\% }\end{array}$ \\
\hline & $\begin{array}{c}\mathbf{0} \\
0.0 \%\end{array}$ & $\begin{array}{c}\mathbf{0} \\
0.0 \%\end{array}$ & $\begin{array}{c}\mathbf{1} \\
16.7 \%\end{array}$ & $\begin{array}{c}\mathbf{0} \\
0.0 \%\end{array}$ & $\begin{array}{c}\mathbf{0} \\
0.0 \%\end{array}$ & $\begin{array}{c}\mathbf{0} \\
0.0 \%\end{array}$ & $\begin{array}{l}100 \% \\
0.0 \%\end{array}$ \\
\hline & $\begin{array}{c}\mathbf{0} \\
0.0 \%\end{array}$ & $\begin{array}{c}\mathbf{0} \\
0.0 \%\end{array}$ & $\begin{array}{c}\mathbf{0} \\
0.0 \%\end{array}$ & $\stackrel{1}{16.7 \%}$ & $\begin{array}{c}\mathbf{0} \\
0.0 \%\end{array}$ & $\begin{array}{c}\mathbf{0} \\
0.0 \%\end{array}$ & $\begin{array}{l}100 \% \\
0.0 \%\end{array}$ \\
\hline & $\begin{array}{c}\mathbf{0} \\
0.0 \%\end{array}$ & $\begin{array}{c}\mathbf{1} \\
16.7 \%\end{array}$ & $\begin{array}{c}\mathbf{0} \\
0.0 \%\end{array}$ & $\begin{array}{c}\mathbf{0} \\
0.0 \%\end{array}$ & $\begin{array}{c}1 \\
16.7 \%\end{array}$ & $\begin{array}{c}\mathbf{0} \\
0.0 \%\end{array}$ & $\begin{array}{l}50.0 \% \\
50.0 \%\end{array}$ \\
\hline & $\begin{array}{c}\mathbf{0} \\
0.0 \%\end{array}$ & $\begin{array}{c}\mathbf{0} \\
0.0 \%\end{array}$ & $\begin{array}{c}\mathbf{0} \\
0.0 \%\end{array}$ & $\begin{array}{c}\mathbf{0} \\
0.0 \%\end{array}$ & $\begin{array}{c}\mathbf{0} \\
0.0 \%\end{array}$ & $\begin{array}{c}\mathbf{1} \\
16.7 \%\end{array}$ & $\begin{array}{l}100 \% \\
0.0 \%\end{array}$ \\
\hline & $\begin{array}{l}100 \% \\
0.0 \%\end{array}$ & $\begin{array}{r}0.0 \% \\
100 \%\end{array}$ & $\begin{array}{l}100 \% \\
0.0 \%\end{array}$ & $\begin{array}{l}100 \% \\
0.0 \%\end{array}$ & $\begin{array}{l}100 \% \\
0.0 \%\end{array}$ & $\begin{array}{l}100 \% \\
0.0 \%\end{array}$ & $\begin{array}{l}83.3 \% \\
16.7 \%\end{array}$ \\
\hline & 1 & 2 & & ${ }^{4}$ & 5 & 6 & \\
\hline
\end{tabular}

D. Result Analysis:

Following table shows the analysis of results collected for different number of test images for both databases. The numeric notation used for types of Expressions is: 1 to 6 for Angry, Disgust, Fear, Happy, Sad, and Surprise respectively. 


\begin{tabular}{|c|c|c|c|c|c|c|c|c|}
\hline \multicolumn{7}{|c|}{ Results for JAFFE Database } \\
\hline $\begin{array}{c}\text { No of } \\
\text { Test } \\
\text { Images }\end{array}$ & 1 & 2 & 3 & 4 & 5 & 6 & $\begin{array}{c}\text { LBP with } \\
\text { Euclidian } \\
\text { distance }\end{array}$ & $\begin{array}{c}\text { LBP with } \\
\text { Neural } \\
\text { Network }\end{array}$ \\
\hline 04 & 00 & 00 & 02 & 00 & 00 & 02 & $80 \%$ & $50 \%$ \\
\hline 06 & 01 & 01 & 01 & 01 & 01 & 01 & $73 \%$ & $83 \%$ \\
\hline 10 & 01 & 01 & 03 & 01 & 01 & 03 & $54 \%$ & $50 \%$ \\
\hline 15 & 02 & 02 & 04 & 01 & 03 & 03 & $73 \%$ & $50 \%$ \\
\hline 20 & 03 & 03 & 03 & 04 & 03 & 04 & $68 \%$ & $47 \%$ \\
\hline 30 & 05 & 05 & 05 & 05 & 05 & 05 & $70 \%$ & $30 \%$ \\
\hline \multicolumn{8}{|c|}{ Results for IFE Database } \\
\hline $\begin{array}{c}\text { No of } \\
\text { Test } \\
\text { Images }\end{array}$ & 1 & 2 & 3 & 4 & 5 & 6 & $\begin{array}{c}\text { Luclidian } \\
\text { Type of Expressions }\end{array}$ & $\begin{array}{c}\text { Neural } \\
\text { distance }\end{array}$ \\
\hline 04 & 00 & 00 & 02 & 00 & 00 & 02 & $50 \%$ & $75 \%$ \\
\hline 06 & 01 & 01 & 01 & 01 & 01 & 01 & $83 \%$ & $67 \%$ \\
\hline 10 & 01 & 01 & 03 & 01 & 01 & 03 & $70 \%$ & $70 \%$ \\
\hline 15 & 02 & 02 & 04 & 01 & 03 & 03 & $87 \%$ & $93 \%$ \\
\hline 20 & 03 & 03 & 03 & 04 & 03 & 04 & $75 \%$ & $75 \%$ \\
\hline 30 & 05 & 05 & 05 & 05 & 05 & 05 & $93 \%$ & $73 \%$ \\
\hline
\end{tabular}

\section{CONCLUSION}

The work in this paper concentrates on performance of Local Binary Pattern for illumination invariant facial expression recognition for two different databases. LBP works satisfactorily well, even though the images are not pre-processed to remove illumination changes. It is concluded from the results that LBP turn to be an efficient method for feature extraction for the purpose of expression recognition, whatever may be the classifier. It works reasonably well with both databases, namely, JAFFE and IFE. The number of LBP feature points can be extracted from different regions of face and combined features can be used for better recognition rate.

\section{REFERENCES}

[1] A. Mehrabian, "Communication without words", psychology today, Vol. 2, No. 4, pp. 53-56, 1968.

[2] P. Ekman, Emotion in the Human Face. Cambridge Univ. Press, 1982.

[3] S.cTai,K.C.Chung. "Automatic Facial Expression Recognition System using Neural Networks". IEEE Region 10 conference,Oct-Nov 2007.

[4] S. Shan, W. Gao, B. Cao, and D. Zhao, "Illumination normalization for robust face recognition against varying lighting conditions," in Proc. IEEE Workshop on AMFG, 2003, pp. 157-164.

[5] M. Savvides and V. Kumar, "Illumination normalization using logarithm transforms for face authentication," in Proc. IAPR AVBPA, 2003, pp. 549-556.

[6] Weiong Chen, Meng Joo Er, Shiqian Wu, "Illumination compensation and Normalization for Robust Face Recognition Using Discrete Cosine Transform in Logarithm Domain", IEEE transactions on Systems, Man and Cybernatics-Part B: Cybernetics, Vol. 36, No. 2, April 2006.

[7] T. Ahonen, A. Hadid, M. Pietikainen, "Face description with local binary patters: application to face recognition", IEEE transactions on pattern analysis and machine intelligence, Vol. 28, No. 12, Dec 2006.

[8] Y. Adini, Y. Moses, and S. Ullman, "Face recognition: the problem of compensating for changes in illumination direction," IEEE Trans. Pattern Anal. Mach. Intell., vol. 19, no. 7, pp. 721-732, Jul. 1997.

[9] B. Fasel, juergen Luettin, "Automatic facial expression analysis: a survey", the journal of the pattern recognition society, 2002.

[10] Maja Pantic, Leon J.m. Rothkrantz, "Automatic Analysis of Facial Expressions: The State of the Art", IEEE transactions on pattern analysis and machine intelligence, Vol. 22, No. 12, December 2000.

[11] T. Ojala, M. Pietikainen, D. Harwood, "A comparative study of texture measures with classifications based on featured distribution, Pattern Recognition 29(1) (1996) 51-59.

[12] Caifeng shan, Shaogang Gong, Peter McOwan, "Facial expression recognition based on Local Binary Patterns: A comprehensive study", Journal of Image and vision computing, Elsevier, 2008.

[13] Caifeng shan, Shaogang Gong, Peter McOwan, "Robust Facial expression recognition using Local Binary Patterns", 2005 IEEE.

[14] S Moore, R. Bowden, "Local binary patterns for multi-view facial expression recognition", Journal of Computer Vision and Image Understanding, Elsevier 2011.

[15] JAFFE Database - http://www.kasrl.org/jaffe info.html

[16] Liying Ma, Yegui Xiao, K. Khorasani, Rabab Kreidieh Ward, "A New Facial Expression Recognition Technique using 2 D DCT and K-Means Algorithm", International Conference on Image Processing, 2004.

[17] W. Zheng, H. Tang, Z. Lin, T. S. Huang, "A Novel Approach to Expression Recognition from Non-frontal Face Images", IEEE 12th International Conference on Computer Vision (ICCV), 2009.

[18] Jung-Wei Hong, Kai-Tai Song, "Facial Expression Recognition under Illumination Variation”, 2007 IEEE.

[19] M. Pantic, L. J. M. Rothkrantz, "Facial Action Recognition for Facial Expression Analysis From Static Face Images" IEEE Transactions on Systems, Man and Cybernetics -, VOL. 34, NO. 3, JUNE 2004.

[20] Nazil Perveen, Shubhrata Gupta, Keshri Verma, "Facial Expression Classification Using Statistical, Spatial Features and Neural Network, International Journal of Advances in Engineering \& Technology, July 2012. 
[21] Sreevatsan. A.N, Sathish Kumar. K.G, Rakeshsharma. S and Mohd. Mansoor Roomi, "Emotion Recognition from Facial Expressions: A Target Oriented Approach Using Neural Network", ICVGIP, 2004. 